\title{
Testing the Nominal-to-Real Transformation
}

Kongsted, Hans Christian

Publication date:

2002

Document version

Early version, also known as pre-print

Citation for published version (APA):

Kongsted, H. C. (2002). Testing the Nominal-to-Real Transformation. Department of Economics, University of Copenhagen. 


\title{
DISCUSSION PAPERS Department of Economics University of Copenhagen
}

\section{$02-06$}

Testing the Nominal-to-Real Transformation

\author{
Hans Christian Kongsted
}

Studiestræde 6, DK-1455 Copenhagen K., Denmark

Tel. +45 35323082 - Fax +45 35323000

http://www.econ.ku.dk 


\title{
Testing the Nominal-to-Real Transformation
}

\author{
Hans Christian Kongsted * \\ Institute of Economics, University of Copenhagen \\ Studiestræde 6, DK-1455 Copenhagen K, Denmark \\ E-mail Hans.Christian.Kongsted@econ.ku.dk
}

March 2002

\begin{abstract}
Nominal-to-real data transformations are routinely used in empirical work. A common example is the transformation of nominal money and prices to real money and the rate of inflation. This paper establishes the necessary and sufficient condition for a transformation to reduce the order of integration of an $\mathrm{I}(2)$ vector process while retaining the cointegrating relations among the variables. A particular direction in which the condition potentially fails is often treated by assumption in applied work. In this case, the transformed process satisfies a well-specified vector equilibrium model, yet I(1) inference and interpretation based on the real transformed system is invalidated. An easy-to-implement sequential test of the transformation based on $\mathrm{I}(1)$ cointegration methods is suggested. It demonstrates good size and power properties in a small-scale simulation experiment. An empirical example illustrates the need to test the nominal-to-real transformation.
\end{abstract}

Key words: Cointegration, stochastic trend, I(2), price homogeneity, Monte Carlo experiment.

JEL classification: C32, C51, C52, E41

${ }^{*}$ Phone +453532 3076, fax +453532 3064. I thank Graham Elliott, Clive Granger, David Hendry, Katarina Juselius, Søren Johansen, Allan Würtz, and seminar participants at UCSD, University of Southern California, George Washington University, the Norwegian University of Science and Technology, and the ESEM 1999 in Santiago de Compostela for useful comments. Financial support from the Danish-American Fulbright Commision and the Danish Social Sciences Research Council is gratefully acknowledged. 


\section{Introduction}

This paper examines certain data transformations commonly applied to nominal time series, so-called nominal-to-real transformations. ${ }^{1}$ Nominal time series are often modelled statistically as being integrated of order two, denoted $\mathrm{I}(2) .^{2}$ The transformation aims to reduce the order of integration while preserving the cointegrating relations that exist among the variables, including the so-called polynomially cointegrating relations. Finding empirical validity of a real transformation would be in accordance with a large body of economic theory that predicts long-run price homogeneity. Moreover, it offers the convenience of being able to apply the comparatively simple I(1) tools in the real system as opposed to more elaborate $\mathrm{I}(2)$ techniques needed for analyzing the nominal system.

Studies that involve the long-run relationships between nominal I(2) time series are prevalent in the literature. Examples include open economy pricing relationships between domestic prices, unit labour costs, and import prices, e.g. Banerjee and Russell (2001) and Banerjee, Cockerell and Russell (2001), the long- and medium-run relationships among commodity prices and general price indices, Juselius (1999), and monetary relationships that involve money stock measures and consumer prices (or alternative aggregate price indices), e.g. Ericsson, Hendry and Prestwich (1998), Muscatelli and Pirelli (2000), Juselius (2001), and Coenen and Vega (2001).

Money demand analysis is arguably the leading example of applications of nominal-to-real transformations. According to most theories, the steadystate demand for real money should be unit free and homogeneous of degree zero in nominal variables, e.g. Doornik et al. (1998). In a standard specification, the empirical analysis is based on real money, $m_{t}-p_{t}{ }^{3}$ a measure of the scale of transactions, and one or more measures of the opportunity cost of holding money. For concreteness, consider the real income, $y_{t}$, the rate of inflation, $\Delta p_{t}$, and the spread between the long-term interest rate and the own yield of money, denoted $R_{t}$. Those variables, including the rate of inflation, are then treated empirically as first-order integrated processes. By implication, nominal money, $m_{t}$, and the price level, $p_{t}$, are $\mathrm{I}(2)$, sharing a common stochastic trend and thus cointegrating to $\mathrm{I}(1) .{ }^{4}$ In this case, the

\footnotetext{
${ }^{1}$ The transformation will be referred to as nominal-to-real and the case of a single $\mathrm{I}(2)$ common trend will be considered in the introduction and the examples. The analytical results of the paper encompass general forms of the transformation as well as general values of the rank indices.

${ }^{2}$ See Haldrup (1998) for a recent survey of the econometric analysis of $\mathrm{I}(2)$ variables.

${ }^{3}$ Lowercase denotes log-transformed variables.

${ }^{4}$ This is the case denoted $\mathrm{CI}(2,1)$ in the terminology of Granger (1986). Stock and
} 
nominal-to-real transformation relies on a single I(2) common trend being loaded proportionately into money and prices. The auxiliary assumption is that neither $y_{t}$ nor $R_{t}$ is integrated of order two. In effect, the $\mathrm{I}(2)$ component of nominal income has been successfully removed in constructing the real measure, $y_{t}$, whereas money and prices are assumed to embody identical nominal components.

A nominal-to-real transformation is often based on theoretical beliefs about the nature of long-run relationships. The main argument of the present paper is that the validity of the transformation for any particular set of measurements needs to be empirically tested. Clearly, measurement issues in terms of money, prices, and the choice of a scale variable (income, total final expenditure, or wealth) have been at the center of a large body of studies of aggregate money demand relationships, see Ericsson (1998). Empirical examples to further substantiate the claim that testing is needed will be provided in the empirical section below.

The main contribution of the present paper is to characterize the cases in which the transformation suggested by theory does not succeed in eliminating the $\mathrm{I}(2)$ component and the implications for the analysis of real transformed variables. Kongsted (1998) pointed out that long-run price homogeneity should be satisfied not only by those cointegrating combinations which reduce the order of integration to zero (possibly in conjunction with first differences of the process), but also by a separate set of linear combinations that cointegrate only from $\mathrm{I}(2)$ to $\mathrm{I}(1)$. The present paper shows that although satisfying homogeneity in terms of the former set of cointegrating combinations is sufficient to ensure the existence of a vector equilibrium correction (VEC) model in terms of the real transformed variables, it is in general not sufficient to ensure the elimination of the $\mathrm{I}(2)$ component. In turn, the full condition for a valid nominal-to-real transformation requires that all linear combinations of the variables integrated of an order less than two should be expressed in real terms.

In applied work the validity of the transformation is very often treated by assumption, or only part of the full condition is tested. Here, the sequential testing approach as suggested in Kongsted (1998) to testing the full condition is applied. Although it requires an analysis of the original nominal system, it essentially relies on the repeated application of I(1) techniques. The sequential approach leads to a consistent test of the nominal-to-real

Watson (1993) and Doornik, Hendry and Nielsen (1998) address the econometric issues involved in analyzing $\mathrm{I}(2)$ monetary data and examine U.S. and U.K. data, respectively. They also provide references to previous work. 
transformation and is found to have reasonable size and power properties in a simple model that underlies the simulation experiment. Moreover, if the transformation is rejected, the test will provide information on exactly where homogeneity is lacking and help predicting the likely consequences for the analysis of the real transformed system.

The outline of the paper is as follows: Section 2 establishes the necessary and sufficient conditions for a valid transformation and examines the properties of the real transformed process. A money demand example is provided in order to fix ideas. Section 3 outlines the statistical analysis and the asymptotic properties of the sequential testing approach. Section 4 provides a simulation experiment based on a simple trivariate data generating process. Section 5 reviews some published applications based on comparatively long data sets and finds strong empirical evidence for the need to test the nominal-to-real transformation. Section 6 offers some conclusions.

Some notation is needed throughout. For a $p \times r$ matrix, $\alpha$, of rank $r$, let $\alpha_{\perp}$ denote a basis of the $p \times(p-r)$ orthogonal complement and define $\bar{\alpha}=\alpha\left(\alpha^{\prime} \alpha\right)^{-1}$. For the matrix $\xi$ of dimensions $(p-r) \times s$ and rank $s$, $s<p-r$, define $\alpha_{1}=\bar{\alpha}_{\perp} \xi$ and $\alpha_{2}=\alpha_{\perp} \xi_{\perp}$. The matrices $\alpha, \alpha_{1}$, and $\alpha_{2}$ are then mutually orthogonal. Likewise, for $\beta(p \times r)$ and $\eta(p-r \times s), s<p-r$, define $\beta_{1}=\bar{\beta}_{\perp} \eta$ and $\beta_{2}=\beta_{\perp} \eta_{\perp}$. A tilde denotes a parameter or variable related to a real transformed system.

\section{The nominal-to-real transformation}

This section analyzes the nominal-to-real transformation which is intended to reduce the order of integration of an $\mathrm{I}(2)$ vector time series while preserving the full set of cointegrating relations amongst the variables. First, the assumptions regarding the original process are given and the transformation is defined. Then, the properties of the transformed process are characterized under two sets of conditions. Finally, a simple example is provided in order to fix ideas and to motivate the model used in the simulation experiment in Section 4.

Assume that the vector process $X_{t}$ satisfies the $p$-dimensional vector autoregression

$$
\Delta^{2} X_{t}=\Pi X_{t-1}-\Gamma \Delta X_{t-1}+\varepsilon_{t} .
$$

The term $\varepsilon_{t}$ is assumed to be identically and independently distributed $N(0, \Omega)$ for $t=1,2, \ldots, T$, and the roots of the characteristic polynomial associated with (2.1) are assumed to be either at 1 or outside the unit circle. 
The initial observations, $X_{-1}, X_{0}$, are taken to be fixed for the statistical analysis..$^{5}$

The following assumption on the original vector process, $X_{t}$, is maintained throughout.

Assumption 1: The parameters satisfy the reduced rank conditions

$$
\Pi=\alpha \beta^{\prime} \quad \text { and } \quad \alpha_{\perp}^{\prime} \Gamma \beta_{\perp}=\xi \eta^{\prime}
$$

with $\alpha$ and $\beta$ of full column rank $r<p$ and $\xi$ and $\eta$ of full column rank $s<p-r$. A further rank condition applies by which

$$
\left|\xi_{\perp}^{\prime} \alpha_{\perp}^{\prime}\left(\Gamma \bar{\beta} \bar{\alpha}^{\prime} \Gamma+I-\Gamma\right) \beta_{\perp} \eta_{\perp}\right| \neq 0
$$

Under the reduced rank conditions (2.2) $X_{t}$ has a vector equilibrium correction (VEC) representation. Johansen (1992a) shows that $X_{t}$ is integrated of order two under Assumption 1. The cointegrating properties of $X_{t}$ are related to the reduced rank conditions and can be characterized as follows: The matrix $\beta_{2}=\beta_{\perp} \eta_{\perp}$ defines the loadings of the $\mathrm{I}(2)$ common trends into $X_{t}$ and the linear combinations $\beta_{2}^{\prime} X_{t}$ remain $\mathrm{I}(2)$. The $r+s$ linear combinations $\left(\beta, \beta_{1}\right)^{\prime} X_{t}$ with $\beta_{1}=\bar{\beta}_{\perp} \eta$, both cointegrate from $\mathrm{I}(2)$ to $\mathrm{I}(1)$, although they differ in terms of further cointegration properties. Specifically, the process $\beta_{1}^{\prime} X_{t}$ of dimension $s$ remains $\mathrm{I}(1)$ and enters in (2.1) only through its first difference. The $r$-dimensional process $\beta^{\prime} X_{t}$, although in general also $\mathrm{I}(1)$, enters the model in levels and cointegrates to stationarity with the first differences in the so-called polynomially cointegrating relationships,

$$
S_{t}=\beta^{\prime} X_{t}-\delta \beta_{2}^{\prime} \Delta X_{t}, \quad \delta=\bar{\alpha}^{\prime} \Gamma \bar{\beta}_{2} .
$$

For a special case in which $r>p-r-s$ there will exist linear combinations of variables as defined by $\delta_{\perp}^{\prime} \beta^{\prime} X_{t}$ that cointegrate directly to stationarity. (2.4) is the standard representation which is minimal in the sense that only the I(1) part of $\Delta X_{t}$ is included, see Johansen (1992a). A relationship such as (2.4) which relates the variables and their first-difference as a cointegrating relationship is the focus of much applied work, e.g., concerning the role

\footnotetext{
${ }^{5}$ The case of two lags in terms of $X_{t}$ is considered for ease of notation and without loss of generality for the results presented. Kongsted and Nielsen (2002) examine the analysis of a real-transformed system for the general $\operatorname{VAR}(k)$. The transformation relates to the stochastic part of the vector process. Although deterministic terms are ignored in this section, any realistic implementation would have to account for deterministics as well.
} 
of inflation in real money demand or the relationship between inflation and the markup over production costs.

The following assumption defines the class of transformations considered in this paper.

Assumption 2: The proposed transformation is

$$
\tilde{X}_{t}=\left(\begin{array}{c}
B^{\prime} X_{t} \\
v^{\prime} \Delta X_{t}
\end{array}\right) \equiv\left(\begin{array}{c}
Z_{t} \\
U_{t}
\end{array}\right)
$$

where $B$ is $p \times(r+s), b=B_{\perp}$, and $v$ is $p \times(p-r-s)$ satisfying $\left|v^{\prime} b\right| \neq 0$.

The columns of $B$ supposedly span the linear combinations that reduce the order of integration from two to one (or to zero in special cases as noted above). Often $Z_{t}=B^{\prime} X_{t}$ consists of real-transformed variables. Correspondingly, the matrix $b=B_{\perp}$ reflects a presumption about the way in which the components of $X_{t}$ are affected by the I(2) common trend. The condition on $v$ ensures that a full set of first differences of the original variables, $\Delta X_{t}$, is obtainable from the transformed process, including those needed for polynomial cointegration according to (2.4). Note that Assumption 2 takes the number of $\mathrm{I}(2)$ components of the process, $p-r-s$, as given whereas $r$ and $s$ need not be separately specified in order to construct $\tilde{X}_{t}$.

Having defined the original process, $X_{t}$, and the nominal-to-real transformation we turn to characterizing the properties of the real-transformed process, $\tilde{X}_{t}$. It is instructive first to examine the full condition under which the nominal-to-real transformation is valid and then to contrast with a result that holds under weaker conditions.

The necessary and sufficient condition for the proposed transformation (2.5) to eliminate the common $\mathrm{I}(2)$ trends and retain the cointegrating combinations is stated in Proposition 1.

Proposition 1: The transformed vector process $\tilde{X}_{t}$ is I(1) with cointegrating rank $\tilde{r}=r$ if and only if

$$
b^{\prime}\left(\beta, \beta_{1}\right)=0 .
$$

The set of cointegrating vectors of $\tilde{X}_{t}$ has the representation

$$
\tilde{\beta}^{\prime}=\left(\phi^{\prime},-\bar{\alpha}^{\prime} \Gamma \bar{\beta}_{2} \beta_{2}^{\prime} b\left(v^{\prime} b\right)^{-1}\right)
$$

where $\phi$ is a $(r+s) \times r$ matrix of full rank such that $\beta=B \phi$.

Proof: See the Appendix. 
Proposition 1 holds that all $\mathrm{CI}(2,1)$ cointegrating vectors should be orthogonal to the known matrix $b$. Equivalently, the I(2) loadings matrix, $\beta_{2}$, should equal $b$ (up to a rotation) for a valid transformation. The standard form (2.4) is obtained from (2.7) by the choice $v=b=\beta_{2}$ which is valid under the assumptions maintained by Proposition 1.

The main interest of the present paper lies in cases where some part of (2.6) fails. ${ }^{6}$ Then, the transformed process $\tilde{X}_{t}$ is $\mathrm{I}(2)$, however, its cointegrating properties depend critically on which part of the condition has failed. In particular, the cases $b^{\prime} \beta \neq 0$ and $b^{\prime} \beta_{1} \neq 0$ can be shown to have very different implications.

If the first part, $b^{\prime} \beta=0$, is satisfied, then $\tilde{X}_{t}$ includes the levels terms necessary to reproduce polynomial cointegration among the original variables. In particular, $b^{\prime} \beta=0$ is sufficient to ensure that a VEC representation exists in terms of $\tilde{X}_{t}$. This is irrespective of $b^{\prime} \beta_{1}=0$ or not. The levels term of the original VEC model, $\beta^{\prime} X_{t-1}$, can be obtained as $\phi^{\prime} B^{\prime} \tilde{X}_{t}$ since $\beta=B \phi$ for some $\phi$ of full rank if $b^{\prime} \beta=0$. The VEC representation of $\tilde{X}_{t}$ is

$$
\Delta \tilde{X}_{t}=\tilde{\Pi} \tilde{X}_{t-1}+\tilde{\Gamma}_{1} \Delta \tilde{X}_{t-1}+\tilde{\varepsilon}_{t}
$$

where

$$
\tilde{\Pi}=(B, v)^{\prime}\left(\alpha, \alpha_{1}\right)\left(\begin{array}{cc}
\phi^{\prime} & -\bar{\alpha}^{\prime} \Gamma \bar{\beta}_{\perp} \beta_{\perp}^{\prime} b\left(v^{\prime} b\right)^{-1} \\
0 & -\beta_{1}^{\prime} b\left(v^{\prime} b\right)^{-1}
\end{array}\right) .
$$

See the Appendix for the derivation of (2.8) and (2.9) and the definitions of $\tilde{\Gamma}_{1}$ and $\tilde{\varepsilon}_{t}$. Of particular interest is how $\tilde{r} \equiv \operatorname{rank}(\tilde{\Pi})$ compares to $r$, the rank of the levels coefficient matrix of the original system. Proposition 2 states this relationship.

Proposition 2: If $b^{\prime} \beta=0$ then $r \leq \tilde{r}=r+r_{b}$ where $r_{b}=\operatorname{rank}\left(b^{\prime} \beta_{1}\right) \leq$ $\min (s, p-r-s)$. If $b^{\prime} \beta=0$ and $b^{\prime} \beta_{1} \neq 0$ then $\tilde{X}_{t}$ is I(2) and $r<\tilde{r}$.

Proof: See the Appendix.

Proposition 2 and the VEC representation for the case $b^{\prime} \beta=0$ in (2.8) and (2.9) have important implications for the cointegrating properties of the transformed system. First, the number of cointegrating relations, $\tilde{r}$, among the variables of the transformed vector, $\tilde{X}_{t}$, will in general exceed the number of polynomially cointegrating relations of the original system, $r$. Equality only holds for the special case that also the second part of (2.6) is satisfied, $b^{\prime} \beta_{1}=0$. Second, even if $b^{\prime} \beta=0 \tilde{X}_{t}$ is in general $\mathrm{I}(2)$

\footnotetext{
${ }^{6}$ The transformed process is analyzed subject to (2.6) by Kongsted and Nielsen (2002).
} 
and polynomially cointegrating. Linear combinations of $Z_{t}$ cointegrate from $\mathrm{I}(2)$ to $\mathrm{I}(1)$ but in general need to be combined with $U_{t}$ and $\Delta \tilde{X}_{t}$ in order to cointegrate to stationarity. Clearly, the I(1) component of $\Delta \tilde{X}_{t}$ must derive from $\Delta Z_{t}$. Third, from the representation (2.9) there are $r_{b}$ linear combinations of the $U_{t}$ process which emerge as trivial $\mathrm{CI}(2,1)$ cointegrating vectors. The latter cointegrate to stationarity, in general in combination with $\Delta Z_{t}$. Finally, by rotating the particular set of cointegrating vectors suggested by the above decomposition of $\tilde{\Pi}$, it is seen that any cointegrating vector of the transformed model will correctly reflect the proportions in which the levels of the original set of variables, $X_{t}$, entered in (2.4), that is, $\beta$. The coefficient of $U_{t}$, on the other hand, is not fully determined by the cointegrating properties alone in this extended set of cointegrating vectors.

Before moving on to tests of the nominal-to-real transformation a simple money demand example is provided in order to illustrate the cases distinguished by Propositions 1 and 2 .

Example: ${ }^{7}$ Consider three nominal variables and their adopted measurements for a particular economy under investigation: The money stock, $m_{t}$, nominal income, $y_{t}^{n}$, and the price level, $p_{t}$. Assume that $X_{t}=\left(m_{t}, y_{t}^{n}, p_{t}\right)^{\prime}$ satisfies (2.1) and that Assumption 1 is satisfied with $r=s=1$. There is one $\mathrm{I}(2)$ common trend in the nominal system. Two further assumptions made throughout the example are that the price level, $p_{t}$, is indeed integrated of order two and that there exist real numbers $\rho$ and $\kappa$ defining a generalized velocity relationship in which $m_{t}-\rho y_{t}^{n}+\kappa \Delta p_{t}$ cointegrate to stationarity. If $\rho=1, \quad \kappa=0$ then standard (inverse) velocity cointegrates to stationary directly.

Assume that theory maintains that the nominal variables $m_{t}, y_{t}^{n}$ and $p_{t}$ are equally affected a single nominal trend corresponding to the common $\mathrm{I}(2)$ trend. Then, $\beta_{2}$ is proportional to $b=(1,1,1)^{\prime}$. The real transformed variables are $\tilde{X}_{t}=\left(m_{t}-p_{t}, y_{t}^{n}-p_{t}, \Delta p_{t}\right)^{\prime}$ which correspond to choices of $B$ and $v$ that satisfy Assumption 2,

$$
B=\left(\begin{array}{rr}
1 & 0 \\
0 & 1 \\
-1 & -1
\end{array}\right), \quad v=\left(\begin{array}{l}
0 \\
0 \\
1
\end{array}\right) \text {. }
$$

Case 0: In this baseline case the adopted measurements satisfy the theoretical presumption. The cointegration parameters can be chosen as $\beta_{2}=$

\footnotetext{
${ }^{7}$ The focus here are the nominal variables. The empirical examples provided in Section 5 include additional variables.
} 
$(1,1,1)^{\prime}, \quad \beta=(1,-1,0)^{\prime}, \quad \beta_{1}=(1,1,-2)^{\prime}$, and satisfy (2.6). Real money, $m_{t}-p_{t}$, and real income, $y_{t}^{n}-p_{t}$, are integrated of order (at most) one. The real magnitudes, in turn, cointegrate to stationarity with $\rho=1$ in the standard measure of inverse velocity, $m_{t}-y_{t}^{n}$ (possibly with inflation).

Case 1: Consider a case in which $p_{t}$ is the appropriate deflator in nominal income whereas the adopted money stock measure requires disproportional price adjustment. Real income, $y_{t}^{n}-p_{t}$, is $\mathrm{I}(1)$ whereas $m_{t}$ and $p_{t}$ cointegrate with a parameter $\rho \neq 1$. Real money, $m_{t}-p_{t}$, and standard inverse velocity, $m_{t}-y_{t}^{n}$, are $\mathrm{I}(2)$ processes in this case. The cointegration parameters are $\beta_{2}=(\rho, 1,1)^{\prime}, \beta=(1,-\rho, 0)^{\prime}, \beta_{1}=\left(\rho, 1,-\left(1+\rho^{2}\right)\right)^{\prime}$. Both parts of condition (2.6) are violated for $\rho \neq 1$. $\tilde{X}_{t}$ remains $\mathrm{I}(2)$ and has no VEC representation because the levels term $m_{t}-\rho y_{t}^{n}$ cannot be obtained from $\tilde{X}_{t}$ when $\rho \neq 1 .{ }^{8}$

Case 2: Consider a case in which nominal income corresponds to the adopted measure of money in the sense that the standard inverse velocity measure, $m_{t}-y_{t}^{n}$, cointegrates to I(1). Still, the price measure adopted, $p_{t}$, is not proportional either in money or income. Real money as well as real income remain $\mathrm{I}(2)$ processes and $\tilde{X}_{t}$ is $\mathrm{I}(2)$. The cointegration parameters for this case are $\beta_{2}=(\gamma, \gamma, 1)^{\prime}, \gamma \neq 1, \beta=(1,-1,0)^{\prime}$, and $\beta_{1}=(1,1,-2 \gamma)^{\prime}$. Accordingly, it holds that $b^{\prime} \beta=0$ whereas $b^{\prime} \beta_{1} \neq 0$. The real transformation $\tilde{X}_{t}$ has a VEC representation with cointegrating rank $\tilde{r}=2$.

In conclusion, if $b^{\prime}\left(\beta, \beta_{1}\right) \neq 0$ then the real-transformed process, $\tilde{X}_{t}$, remains $\mathrm{I}(2)$. If $b^{\prime} \beta \neq 0$ the transformation will not include the linear combinations needed for the polynomially cointegrating relations. If $b^{\prime} \beta=0$ a transformed VEC model exists but, in general, $\tilde{X}_{t}$ is still $\mathrm{I}(2)$ and the rank of the levels coefficient matrix is greater than the number of polynomially cointegrating relations, $r$, of the original system. Only for the special case that also $b^{\prime} \beta_{1}=0$ will the transformation produce a real system which is $\mathrm{I}(1)$ and provides a direct relationship between the two sets of cointegrating relations.

\section{A simple test of the transformation}

Cointegration analysis in a real system (2.8) forms the starting point in most empirical studies of money demand relationships, maintaining the assump-

\footnotetext{
${ }^{8} \mathrm{~A}$ special although trivial case is $\rho=0$ in which prices and nominal income are $\mathrm{I}(2)$ whereas money is $\mathrm{I}(1)$.
} 
tion that $\tilde{X}_{t}$ is $\mathrm{I}(1)$. However, treating the validity of the transformation by assumption runs a significant risk in terms of inference on the number and structure of cointegrating relations. According to Proposition 2, the true cointegrating rank of the real transformed time series is only weakly related to $r$ if $b^{\prime} \beta_{1} \neq 0$ and inference should be based on $\mathrm{I}(2)$ methods. Moreover, the existence of cointegrating vectors that pick out linear combinations of variables in first-differences from $U_{t}$, e.g. the rate of inflation, could be the indication of an invalid transformation rather than suggesting stationarity of the latter variables.

Since the implications of the cases $b^{\prime} \beta \neq 0$ and $b^{\prime} \beta_{1} \neq 0$ are quite different there is an interest in determining the source of a failure of the overall condition (2.6). The two cases can be seen to have a natural sequential ordering which fits into the commonly used two-step analysis of I(2) systems, see Kongsted (1998). In effect, the validity of each part can be assessed based on standard methods for analyzing $\mathrm{I}(1)$ variables.

Each cointegrating relation is subject to $p-r-s$ linear restrictions by (2.6). The first part, $b^{\prime} \beta=0$, is parameterized as $\beta=B \varphi$. The orthogonal complement can then be constructed as

$$
\beta_{\perp}=\left(\bar{B} \varphi_{\perp}, b\right)=\left(B_{1}, b\right) .
$$

The second part of (2.6) is formulated as a restriction on the parameter $\eta$ of the second reduced rank condition in (2.2),

$$
\eta=\beta_{\perp}^{\prime} \beta_{1}=\left(B_{1}, b\right)^{\prime} \beta_{1}=\left(\begin{array}{c}
B_{1}^{\prime} \beta_{1} \\
0
\end{array}\right) .
$$

A simple test of (2.6) based on the sequential use of reduced rank regression is derived in Kongsted (1998). The separate restrictions on $\beta$ and $\beta_{1}$ are examined sequentially based on the so-called two-step estimation procedure, see Johansen (1995), Paruolo (1996), and Rahbek et al. (1999) for details. The first step is equivalent to the standard $\mathrm{I}(1)$ reduced rank regression analysis of $X_{t}$, see Johansen (1996, Section 7.2.1). The model is estimated unrestrictedly as well as subject to the restriction on $\beta$. The likelihood ratio test, denoted $Q_{b 1}$, is asymptotically distributed as $\chi^{2}$ with $(p-r-s) r$ degrees of freedom subject to $b^{\prime} \beta=0$. This holds for the I(1) case and for the I(2) case it follows from Johansen (1995), see also Rahbek et al. (1999, Theorem 4.2).

The second step proceeds by estimating $\eta$ unrestrictedly and imposing $b^{\prime} \beta_{1}=0$ as in (3.11). Both estimates are conditioned on the restricted estimate of $\beta$ and the corresponding estimate of $\alpha$. Subject to $b^{\prime}\left(\beta, \beta_{1}\right)=0$ the 
likelihood ratio test of $b^{\prime} \beta_{1}=0$, denoted $Q_{b 2}$, is asymptotically distributed as $\chi^{2}((p-r-s) s)$. This follows by $\eta$ being mixed Gaussian, see Rahbek et al. (1999, Theorem 4.3).

An overall test of (2.6) can then be constructed by choosing the rejection region as the union of the individual rejection regions, i.e. the overall hypothesis is rejected if any of the individual tests reject. The size of each individual test is chosen as $\nu / 2$, by which the size of the overall test is between $\nu / 2$ and $\nu$. As the separate tests are consistent, the sequential procedure is consistent against the alternative $b^{\prime}\left(\beta, \beta_{1}\right) \neq 0$.

\section{Simulation experiment}

This section conducts a small-scale simulation experiment. The aim is to further illuminate the properties of the real transformed system in cases where condition (2.6) fails. The experiment also illustrates the use of the sequential testing procedure in detecting possible departures from the transformation suggested by theory.

The data generation process (DGP) for the experiment is defined by the equations

$$
\begin{aligned}
& X_{1 t}-X_{2 t}=(\rho-1) X_{2 t-1} \\
& \quad+(\gamma(\rho-1)+\kappa \theta) \Delta X_{3 t-1}+\varepsilon_{1 t}-\varepsilon_{2 t} \\
& \Delta X_{2 t}= \gamma \Delta X_{3 t-1}+\varepsilon_{2 t} \\
& \Delta^{2} X_{3 t}= \varepsilon_{3 t} \\
&\left(\varepsilon_{1 t}, \varepsilon_{2 t}, \varepsilon_{3 t}\right)^{\prime} \sim \text { i.i.d.N }(0, I)
\end{aligned}
$$

with $\theta=1+\gamma^{2}\left(1+\rho^{2}\right) \neq 0$. This design is decidedly simple, both in terms of short-run dynamics and the lack of deterministic terms, as well as transparent in the sense that the rank indices and the roots of the characteristic polynomial are independent of the parameters varied in the experiment. It encompasses the money demand example in Section 2 with $X_{1 t}=m_{t}$, $X_{2 t}=y_{t}^{n}$, and $X_{3 t}=p_{t}$. In this interpretation, (4.12) is a generalized velocity equation, (4.13) is the equation for nominal income and (4.14) is the price equation.

The properties of $X_{t}=\left(X_{1 t}, X_{2 t}, X_{3 t}\right)^{\prime}$ for general values of the parameters $\rho, \gamma$, and $\kappa$ are derived in the Appendix. It is shown that (4.12) - (4.14) can be written in the form of (2.1) with $r=1$ and $s=1$. Assumption 1 is satisfied and $X_{t}$ is $\mathrm{I}(2)$. The $\mathrm{CI}(2,1)$ cointegrating vectors are $\beta=(1,-\rho, 0)^{\prime}$ and $\beta_{1}=\left(\rho, 1,-\gamma\left(1+\rho^{2}\right)\right)^{\prime}$. The vector of $\mathrm{I}(2)$ loadings is $\beta_{2}=(\rho \gamma, \gamma, 1)^{\prime}$ 
and the polynomially cointegrating relationship is

$$
S_{t}=X_{1 t}-\rho X_{2 t}-\kappa\left(\rho \gamma \Delta X_{1 t}+\gamma \Delta X_{2 t}+\Delta X_{3 t}\right)
$$

in the standard representation (2.4).

Samples of size $T+50$ are generated for the simulations, $t=-51,-50, \ldots, 0$, $1, \ldots, T$, with $X_{-51}=X_{-50}=0$. The influence of the initial values is effectively removed by discarding 50 pre-sample values. Each experiment is conducted with 10.000 replications where $\varepsilon_{t}$ is replaced by pseudo-random independent drawings in Gauss.

The sample sizes considered are $T=\{50,150,500\} . T=150$ is within the range available in most studies of quarterly macroeconomic data. The results for $T=500$ should bring out a close approximation to the asymptotic properties of the tests considered. Although the focus of the experiment is not a comparison of the small-sample performance of tests, it is useful also to report results for $T=50$. In view of the simplistic nature of the DGP, the latter set of results should be taken as an indication of the kind of results to be expected in applied work on data with a more complicated dynamic structure.

Estimation is based on reduced rank regression as proposed by Johansen (1988). Tests of the transformation are based on repeated application of reduced rank regression according to the two-step I(2) procedure of Johansen (1995), see Kongsted (1998) for the derivation of a sequential test of $b^{\prime}\left(\beta, \beta_{1}\right)=0$ in the two-step procedure. Determination of the cointegrating rank in the real transformed system uses the trace test of Johansen (1988). ${ }^{9}$ Critical values for the test are obtained from MacKinnon, Haug, and Michelis (1999).

The example in Section 2 specified a particular theoretical structure in terms of $B, b$, and $v$. It also provided some motivation for each of the cases considered in which either $\rho$ or $\gamma$ is varied from a baseline case, $\rho=1, \gamma=1$. The parameter $\kappa$ equals -2 throughout. Table 1 summarizes the three cases considered and Table 2 reports the results.

Case 0: $\rho=1, \gamma=1$

The common $\mathrm{I}(2)$ trend has proportional loadings in $X_{1 t}, X_{2 t}$, and $X_{3 t}$. Thus, (2.6) is satisfied and $\operatorname{sp}(b)=\operatorname{sp}\left(\beta_{2}\right)$. The theoretical transformation

\footnotetext{
${ }^{9}$ For convenience the implied restrictions on $\tilde{\Gamma}_{1}$ are not imposed in the simulation experiment. Kongsted and Nielsen (2002) establish that inference on the cointegrating rank is very little affected by ignoring the restriction.
} 
eliminates the $\mathrm{I}(2)$ trend in this case according to Theorem 1. (4.12) provides a polynomially cointegrating relationship in terms of the $\mathrm{I}(1)$ variables $X_{1 t}-$ $X_{2 t}$ and $\Delta X_{3 t}$ with a coefficient of $\kappa \theta=3 \kappa=-6 .^{10}$

The VEC representation in terms of $\tilde{X}_{t}$ has $\tilde{\Pi}=\tilde{\alpha} \tilde{\beta}^{\prime}$ with rank $\tilde{r}=1$ and $\tilde{\Gamma}=I$. The characteristic polynomial has two unit roots (and no further roots). The matrix $\tilde{\alpha}_{\perp}^{\prime} \tilde{\Gamma} \tilde{\beta}_{\perp}$ has full rank (being equal to the identity in this simple case). Table 1 reports a particular decomposition for $\tilde{\Pi}=\tilde{\alpha} \tilde{\beta}^{\prime}$. The cointegrating linear combinations of the transformed process, $\tilde{\beta}^{\prime} \tilde{X}_{t}$, are seen to reflect the polynomially cointegrating relationships among the original set of variables.

The simulation results in Table 2 for Case $0, T=500$ are in accordance with the asymptotics outlined in Section 3. The rejection frequencies are close to 0.05 both for the first-stage test on $\beta, Q_{b 1}$, and for the sequential test on $\beta$ and $\beta_{1}$. Rank determination in the transformed model based also accords well with the asymptotics, see Johansen (1992b). It selects $\tilde{r}=0$ with frequency $0,{ }^{11}$ the true value, $\tilde{r}=1$, with a frequency close to 0.95 , and $\tilde{r} \geq 2$ with frequency close to 0.05 . For smaller values of $T$ the tests tend to be oversized which is in accordance with the findings of numerous other studies, e.g. Doornik et al. (1998).

Case 1: $\rho \neq 1, \gamma=1$

In this case the condition (2.6) is violated and the common $\mathrm{I}(2)$ trend loads disproportionately as $\beta_{2}=(\rho, 1,1)^{\prime}$, see Table 1 . The transformed process, $\tilde{X}_{t}$ remains $\mathrm{I}(2)$. Since $b^{\prime} \beta \neq 0$ there is no valid VEC representation for $\tilde{X}_{t} \cdot{ }^{12}$

Simulation results are reported for five values of $\rho$ and $T=\{50,150,500\}$ in Table 2. ${ }^{13}$ The first-step test on $\beta$ alone, $Q_{b 1}$, and the sequential test appear almost equally powerful in picking up deviations from the baseline $\rho=1$. The power of both tests is more than 0.8 when $\rho$ deviates from the baseline by 1 per cent or more for the central case, $T=150$.

\footnotetext{
${ }^{10}$ This is of the order of magnitude of inflation effects in inverse velocity found, e.g., by Doornik et al. (1998) and Juselius and Toro (1999).

${ }^{11}$ This holds throughout the simulations and is therefore not reported in Table 2.

${ }^{12}$ Accordingly, no results are reported in Table 2 for the analysis of the real transformed system.

${ }^{13}$ Only the first combination of $\rho$ and $T$ is reported for which the rejection frequency equals 1 .
} 
Case 2: $\rho=1, \gamma \neq 1$

In this case $b^{\prime} \beta=0$ is satisfied whereas $b^{\prime} \beta_{1} \neq 0$. Again, the common $\mathrm{I}(2)$ trend affects the variables disproportionately, see Table 1 , and $\tilde{X}_{t}$ is I(2) according to Proposition 1. Contrary to Case 1 a transformed VEC representation exists in terms of $\tilde{X}_{t}$ with the coefficients

$$
\tilde{\Pi}=\left(\begin{array}{ccc}
-1 & 1 & -\kappa \theta+1-\gamma \\
0 & 0 & \gamma-1 \\
0 & 0 & 0
\end{array}\right) \text { and } \tilde{\Gamma}=I \text {. }
$$

The levels coefficient matrix $\tilde{\Pi}$ has rank $\tilde{r}=2$ iff $\gamma \neq 1$. It can be decomposed into the product of $p \times \tilde{r}$ matrices $\tilde{\beta}$ and $\tilde{\alpha}$. Moreover, it can be shown that $\tilde{\alpha}_{\perp}^{\prime} \tilde{\Gamma} \tilde{\beta}_{\perp}=0$ whereas $\left|\tilde{\alpha}_{2}^{\prime}\left(\tilde{\Gamma} \tilde{\beta} \tilde{\alpha}^{\prime} \tilde{\Gamma}+I-\tilde{\Gamma}\right) \tilde{\beta}_{2}\right| \neq 0$. Case 2 has two unit roots in the characteristic polynomial associated with the transformed VEC model. Both are related to the $\mathrm{I}(2)$ common trend that remains in this system.

The general structure of cointegration in the transformed model was derived in Section 2. For the present DGP there are two cointegrating relationships among the transformed variables which can be further characterized as follows. First, it is evident from $\tilde{\beta}$ as reported in Table 1 that components of $X_{t}$ which enter the cointegrating relationships in levels through $Z_{t}=\left(X_{1 t}-X_{3 t}, X_{2 t}-X_{3 t}\right)^{\prime}$, will do so in the same proportions as they entered the polynomially cointegrating relationship of the original system. This holds for any linear combination of the cointegrating vectors. Second, the coefficient of the first-differenced term, $U_{t}=\Delta X_{3 t}$, is in general not pinned down by the cointegrating properties of $\tilde{X}_{t}$. Specifically, for the particular choice of basis for $\tilde{\beta}$ and $\tilde{\alpha}$ reported in Table 1 the coefficient of $\Delta X_{3 t}$ differs from $-\kappa \theta$. Moreover, it is possible to linearly combine the $\tilde{\beta}$-vectors to obtain a vector that excludes $U_{t}$ altogether. Third, $\tilde{X}_{t}$ is $\mathrm{I}(2)$ so $\tilde{\beta}^{\prime} \tilde{X}_{t}$ will in general not be cointegrating to stationarity. Rather, $\tilde{\beta}^{\prime} \tilde{X}_{t}$ and $\tilde{\beta}_{2}^{\prime} \Delta \tilde{X}_{t}$ combine to form polynomially cointegrating relationships. The coefficient of the latter for the basis reported for $\tilde{\beta}$ in Table 1 can be shown to be

$$
\tilde{\delta}=\overline{\tilde{\alpha}}^{\prime} \tilde{\Gamma} \overline{\tilde{\beta}}_{2}=\left(\begin{array}{r}
-\frac{1}{2} \\
\frac{1}{2}
\end{array}\right)
$$

in the standard format (2.4). This is the coefficient of

$$
\tilde{\beta}_{2}{ }^{\prime} \Delta \tilde{X}_{t}=(1,1,0)\left(\Delta\left(X_{1 t}-X_{3 t}\right), \Delta\left(X_{2 t}-X_{3 t}\right), \Delta^{2} X_{3 t}\right)^{\prime} .
$$


In the velocity example, a disproportional price deflator would leave real money and real income $\mathrm{I}(2)$ and a linear combination of their first differences would be cointegrating with the rate of inflation.

Turning to the simulation results, Table 2 shows that the deviations from the baseline in Case 2 are well captured by the sequential test. The power increases fairly rapidly in $1-\gamma$ albeit at a slower rate than for $\rho$-deviations from the baseline. The different rates of convergence of $\beta$ and $\beta_{1}$ that hold in the $\mathrm{I}(2)$ model, see Johansen (1995), are thus reflected in the rejection frequencies for finite samples.

Also reported in Table 2 are the rejection frequencies of the first-step test on $\beta$ alone, $Q_{b 1}$, at a nominal 5 per cent level. The condition $b^{\prime} \beta=0$ is satisfied in Case 2 and it appears that the empirical size remains close to the nominal value and is not systematically affected by the value of $\gamma$ for any given sample size.

The remaining columns in Table 2 regard rank determination by a trace test within the transformed VEC model. Note that the true value of $\operatorname{rank}(\tilde{\Pi})$ is two when $\gamma$ deviates from one. Apart from small variations due to Monte Carlo uncertainty, the frequency of $\tilde{r}=1$ being selected decreases as $\gamma$ deviates from one whereas the outcome $\tilde{r}=2$ becomes more likely. Moreover, as the system contains an $\mathrm{I}(2)$ trend for $\gamma \neq 1$ the $\mathrm{I}(1)$ asymptotic distribution of the trace test no longer applies. Johansen (1995) shows that the distribution shifts out and that the trace test rejects the true hypothesis that $\tilde{r} \leq 2$ with a size that exceeds the nominal level when based on I(1) critical values. Indeed, in the simulations a large number of simulations lead to the outcome $\tilde{r}=3$.

\section{$5 \quad$ Empirical Examples}

The determinants of the long-run demand for money have been the subject of a large number of studies using a variety of methods and measurements of income, prices, and interest rates. The list includes early regressionbased studies such as Goldfeld $(1973,1976)$ and recent studies based on cointegration methods, e.g. Baba, Hendry, and Starr (1992), Friedman and Kuttner (1992), Stock and Watson (1993), Ericsson, Hendry, and Prestwich (1998), and Muscatelli and Spinelli (2000).

This section examines the validity of the nominal-to-real transformation for three annual data sets that cover comparatively long periods. The data

sets have been analyze in studies for the United States by Stock and Watson (1993), for the United Kingdom by Ericsson et al. (1998), and for Italy by 
Muscatelli and Spinelli (2000). Table 3 outlines the main characteristics of the data.

The basic vector of variables is $X_{t}=\left(m_{t}, p_{t}, y_{t}, R_{t}\right)^{\prime}$ where $y_{t}$ is real income and $R_{t}$ contains one or more measures of the own and alternative rates of interest. The U.S. and U.K. data measure the price level as the deflator that corresponds to the real income definition. Muscatelli and Spinelli (2000, p. 722), on the other hand, argue that a cost-of-living index is preferable to the GDP deflator as the former "is likely to be a more important determinant of transactions balances." In addition, Muscatelli and Spinelli examine the role of the rate of inflation in the long-run demand for real money, i.e. a polynomially cointegrating relationship of the form (2.4).

Table 4 reports the sequential test of the nominal-to-real transformation for the three data sets. The results are based on vector equilibrium correction models with four lags. ${ }^{14}$ This corresponds to the choice of three lags in first differences in the real money equilibrium correction model estimated by Muscatelli and Spinelli (2000, p. 730). A single cointegrating relationship among the levels $(r=1)$ and one common $\mathrm{I}(2)$ trend $(p-r-s=1)$ have been imposed throughout. Stock and Watson (1993) and Muscatelli and Spinelli (2000) argue that $m_{t}$ and $p_{t}$ should be modelled as $\mathrm{I}(2)$ variables whereas Ericsson et al. (1998) conclude in favour of the data being I(1). Applying the rank test procedure of Rahbek et al. (1999) suggests that the U.S. and U.K. data are I(2). The conclusion is found to depend on the inclusion of war dummies in the case of Italy. Finally, the theoretical hypothesis maintained in Table 4 is that $m_{t}$ and $p_{t}$ are $\mathrm{I}(2)$ with equal loadings whereas the remaining variables are at most integrated of order one.

Table 4 contains two sets of results for each country. The columns labeled "Constant and trend" employ the deterministic specification suggested by Rahbek et al. (1999). ${ }^{15}$ The nominal-to-real transformation cannot be rejected at usual levels of significance for the U.S. or the U.K. The tests of both parts of (2.6) have $p$-values of 0.2 or more. On the other hand, the transformation is rejected in the Italian case. Although the validity of the first part of (2.6), $b^{\prime} \beta=0$, cannot be rejected, the second part, $b^{\prime} \beta_{1}=0$, must be firmly rejected.

The columns labeled "Constant" restrict the model to exclude any linear trend component in the polynomially cointegrating combinations. Although,

\footnotetext{
${ }^{14}$ This is sufficient to capture the autoregressive structure in the U.S. and U.K. data. For Italy there is evidence of autocorrelated errors from tests at the level of the full system although single-equation tests cannot reject the null of no serial correlation.

${ }^{15}$ The case of Italy also included war dummies as detailed in Muscatelli and Spinelli (2000).
} 
formally, the exclusion of the trend is rejected for all three countries, ${ }^{16}$ this is the specification adopted by the original studies. Conclusions concerning the validity of the nominal-to-real transformation remain unaltered. The evidence for price homogeneity of the levels cointegrating combination now appears weaker for the U.K. and for Italy with $p$-values less than 0.1.

The results for the Italian case can be related to Muscatelli and Spinellis findings. Using single-equation methods they confirmed long-run price homogeneity of the money demand relationship, essentially establishing that $b^{\prime} \beta=0$. Moreover, they found the estimates of the income effect and the own and alternative rate effects to be in accordance with a priori beliefs. On the contrary, in several different specifications the inflation coefficient estimate turned out to be insignificant or signed contrary to a priori considerations. These findings are in accordance with the predictions of Section 2 for the case that $b^{\prime} \beta=0$ but $b^{\prime} \beta_{1} \neq 0$ : The true cointegrating rank is greater than one and the polynomially cointegrating relationship obtained by imposing only one cointegrating vector will be some linear combination of the "true" money demand relationship, possibly with a significant effect of the rate of inflation, and another relationship combining the rate of inflation with first-differences of the real transformed variables. The coefficients of real money, real income, and the interest rate variables is correctly reflected by the combined relationship whereas the coefficient of the rate of inflation cannot in general be identified as an inflation effect in the demand for real balances.

\section{Conclusions}

The paper has presented a formal characterization of cases in which the nominal-to-real transformation is invalid. The main result in Proposition 2 shows that $\mathrm{I}(1)$ inference and interpretation of the real transformed system need not be valid even though the system is transformed according to theoretical considerations that are satisfied by the polynomially cointegrating relations.

Specifically, the transformation may fail in terms of the remaining $\mathrm{CI}(2,1)$ cointegrating combinations that enter the VEC model in terms of firstdifferences only. If the transformed process is then erroneously assumed to be $\mathrm{I}(1)$, the system could be interpreted as being associated with direct

\footnotetext{
${ }^{16}$ The likelihood ratio tests of excluding the trend for the U.S., U.K. and Italian cases are 5.05, 21.56, and 6.56, respectively, with limiting $\chi^{2}(1)$ distributions, see Rahbek et al. (1999, Corollary 4.1).
} 
cointegration among the real magnitudes and apparently stationary first differences of the nominal variables. As shown in Section 2, in fact the transformed process in this case is $\mathrm{I}(2)$ and embodies polynomial cointegration among the real transformed variables.

The sequential test is suggested as a simple and consistent test based on standard I(1) methods. It enables a test of each part of (2.6) as well as a joint test. There are alternative $\mathrm{I}(2)$ methods which allow a joint test of the hypothesis $b^{\prime}\left(\beta, \beta_{1}\right)=0$. Most notably the $\mathrm{I}(2)$ maximum likelihood approach of Johansen (1997) which relies on a different parameterization of the model and a different estimation algorithm.

\section{Appendix}

\section{Proof of Proposition 1:}

The following results will be helpful for the proof: First, if $\left|v^{\prime} b\right| \neq 0$ then $\left|B^{\prime} V\right| \neq 0$ where $V=v_{\perp}$ and $\operatorname{rank}(B, v)=p$ so that $I=a v^{\prime}+c B^{\prime}$ holds with $a=b\left(v^{\prime} b\right)^{-1}$ and $c=V\left(B^{\prime} V\right)^{-1}$, see Hansen and Johansen (1998). Secondly, under (2.6) it holds that $s p(B)=s p\left(\beta, \beta_{1}\right)$ so that $B=\left(\beta, \beta_{1}\right) A$ for a non-singular matrix $A$. If $b^{\prime} \beta=0$ then $\beta=B \phi$ for some $(r+s) \times r$ matrix $\phi$ of full column rank.

Necessity of condition (2.6): $\tilde{X}_{t}$ includes linear combinations of the levels of $X_{t}$ in terms of $Z_{t}=B^{\prime} X_{t}$. Using the relationship $I=\beta \bar{\beta}^{\prime}+\beta_{1} \bar{\beta}_{1}^{\prime}+\beta_{2} \bar{\beta}_{2}^{\prime}$ we get

$$
Z_{t}=B^{\prime}\left(\beta \bar{\beta}^{\prime}+\beta_{1} \bar{\beta}_{1}^{\prime}+\beta_{2} \bar{\beta}_{2}^{\prime}\right) X_{t}
$$

If either part of (2.6) fails then the I(2) component, $\beta_{2}^{\prime} X_{t}$, will carry over to the transformed process which shows necessity of (2.6).

Sufficiency of condition (2.6): It is illuminating to show sufficiency in three steps: First, we establish that $\tilde{X}_{t}$ is integrated at most of order one. Secondly, we show that $\tilde{X}_{t}$ satisfies a reduced rank VEC representation. Finally, a result from Johansen (1996) can be applied to show that $\tilde{X}_{t}$ is indeed $\mathrm{I}(1)$ with cointegrating rank $\tilde{r}=r$.

i) To establish that $\tilde{X}_{t}$ is integrated at most of order one: $U_{t}=v^{\prime} \Delta X_{t}$ is integrated at most of order one by the fact that it obtains by first-differencing of linear combinations of an $\mathrm{I}(2)$ process, $Z_{t}=B^{\prime} X_{t}$ is a non-singular transformation of an $\mathrm{I}(1)$ process, $B^{\prime} X_{t}=A^{\prime}\left(\beta, \beta_{1}\right)^{\prime} X_{t}$. 
ii) To show that $\tilde{X}_{t}$ satisfies a reduced rank VEC representation: Insert $\Pi=\alpha \beta^{\prime}$ in (2.1) to obtain the VEC representation,

$$
\Delta^{2} X_{t}=\alpha \beta^{\prime} X_{t-1}-\Gamma \Delta X_{t-1}+\varepsilon_{t} .
$$

Multiply by $(B, v)^{\prime}$ and use the relation $\Delta X_{t}=c \Delta Z_{t}+a U_{t}$ to obtain

$$
\left(\begin{array}{c}
\Delta^{2} Z_{t} \\
\Delta U_{t}
\end{array}\right)=\left(\begin{array}{c}
B^{\prime} \alpha \beta^{\prime} X_{t-1} \\
v^{\prime} \alpha \beta^{\prime} X_{t-1}
\end{array}\right)-\left(\begin{array}{c}
B^{\prime} \Gamma\left(c \Delta Z_{t-1}+a U_{t-1}\right) \\
v^{\prime} \Gamma\left(c \Delta Z_{t-1}+a U_{t-1}\right)
\end{array}\right)+\left(\begin{array}{c}
B^{\prime} \varepsilon_{t} \\
v^{\prime} \varepsilon_{t}
\end{array}\right) .
$$

The levels term $\beta^{\prime} X_{t-1}$ is a linear combination of $Z_{t-1}=B^{\prime} X_{t-1}$ as $b^{\prime} \beta=0$. Collect terms in levels and first differences of the transformed process,

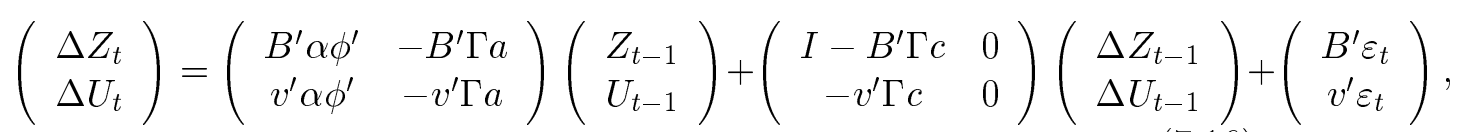

which is now a VEC model for the transformed process,

$$
\Delta \tilde{X}_{t}=\tilde{\Pi} \tilde{X}_{t-1}+\tilde{\Gamma}_{1} \Delta \tilde{X}_{t-1}+\tilde{\varepsilon}_{t}
$$

with $\tilde{\varepsilon}_{t}=(B, v)^{\prime} \varepsilon_{t}$ and

$$
\tilde{\Gamma}_{1}=\left(\begin{array}{cc}
I-B^{\prime} \Gamma c & 0 \\
-v^{\prime} \Gamma c & 0
\end{array}\right)
$$

In order to derive the structure of $\tilde{\Pi}$ it is useful to apply the relation $\Gamma=$ $\Gamma \bar{\beta} \beta^{\prime}+\left(\alpha \bar{\alpha}^{\prime} \Gamma \bar{\beta}_{1}+\alpha_{1}\right) \beta_{1}^{\prime}+\alpha \bar{\alpha}^{\prime} \Gamma \bar{\beta}_{2} \beta_{2}^{\prime}$ which is a consequence of Assumption 1, see Paruolo and Rahbek (1999). The term $\Gamma a$ can be rewritten as

$$
\Gamma a=\left[\Gamma \bar{\beta} \beta^{\prime} b+\left(\alpha \bar{\alpha}^{\prime} \Gamma \bar{\beta}_{1}+\alpha_{1}\right) \beta_{1}^{\prime} b+\alpha \bar{\alpha}^{\prime} \Gamma \bar{\beta}_{2} \beta_{2}^{\prime} b\right]\left(v^{\prime} b\right)^{-1} .
$$

The first and second terms vanish by (2.6) which leaves $\Gamma a=\alpha \bar{\alpha}^{\prime} \Gamma \bar{\beta}_{2} \beta_{2}^{\prime} b\left(v^{\prime} b\right)^{-1}$. Inserting in (7.16) we get the following expression for $\tilde{\Pi}$,

$$
\tilde{\Pi}=(B, v)^{\prime} \alpha\left(\phi^{\prime},-\bar{\alpha}^{\prime} \Gamma \bar{\beta}_{2} \beta_{2}^{\prime} b\left(v^{\prime} b\right)^{-1}\right),
$$

where $\alpha$ and $\phi$ have full column rank $r$ and therefore $\operatorname{rank}(\tilde{\Pi})=r$. Defining $\tilde{\alpha}=(B, v)^{\prime} \alpha$ we get the decomposition $\tilde{\Pi}=\tilde{\alpha} \tilde{\beta}^{\prime}$ where $\tilde{\beta}$ is given by (2.7).

iii) From Corollary 4.3 of Johansen (1996) it follows that when $\tilde{X}_{t}$ is integrated of order at most one and $\tilde{\Pi}$ has reduced rank $r<p, \tilde{X}_{t}$ is indeed $\mathrm{I}(1)$ with cointegrating rank $r$.

This completes the proof of Proposition 1. 


\section{Proof of Proposition 2:}

Proposition 2 assumes that $b^{\prime} \beta=0$ so the above derivation of (7.16) applies. Since $b^{\prime} \beta_{1}$ is not restricted it is useful to rewrite (7.17) as

$$
\Gamma a=\left[\Gamma \bar{\beta} \beta^{\prime} b+\alpha \bar{\alpha}^{\prime} \Gamma \bar{\beta}_{\perp} \beta_{\perp}^{\prime} b+\alpha_{1} \beta_{1}^{\prime} b\right]\left(v^{\prime} b\right)^{-1} .
$$

Now only the first term in parentheses vanishes and

$$
\begin{aligned}
\tilde{\Pi} & =(B, v)^{\prime}\left(\alpha \phi^{\prime},-\alpha \bar{\alpha}^{\prime} \Gamma \bar{\beta}_{\perp} \beta_{\perp}^{\prime} b\left(v^{\prime} b\right)^{-1}-\alpha_{1} \beta_{1}^{\prime} b\left(v^{\prime} b\right)^{-1}\right) \\
& =(B, v)^{\prime}\left(\alpha, \alpha_{1}\right)\left(\begin{array}{cc}
\phi^{\prime} & -\bar{\alpha}^{\prime} \Gamma \bar{\beta}_{\perp} \beta_{\perp}^{\prime} b\left(v^{\prime} b\right)^{-1} \\
0 & -\beta_{1}^{\prime} b\left(v^{\prime} b\right)^{-1}
\end{array}\right) .
\end{aligned}
$$

This is the product of three matrices: $(B, v)$ is $p \times p$ of full rank whereas the second and third have dimensions $p \times(r+s)$ and $(r+s) \times p$, respectively. Thus, $\operatorname{rank}(\tilde{\Pi}) \leq r+s<p$. Since $\phi$ has full column rank it holds that $\operatorname{rank}(\tilde{\Pi}) \geq r$. Denoting $\operatorname{rank}\left(b^{\prime} \beta_{1}\right)$ by $r_{b}$ then $r \leq \tilde{r}=r+r_{b} \leq r+\min (s, p-$ $r-s)$.

If $b^{\prime} \beta=0$ and $b^{\prime} \beta_{1} \neq 0$ then $r_{b}=\operatorname{rank}\left(b^{\prime} \beta_{1}\right)>0$ and therefore $r<\tilde{r}$. The expression (7.15) shows that $\tilde{X}_{t}$ is $\mathrm{I}(2)$.

This completes the proof of Proposition 2.

\section{The Simulation Model:}

The model (4.12) - (4.14) can be rewritten as (2.1) with

$$
\Pi=\left(\begin{array}{ccc}
-1 & \rho & 0 \\
0 & 0 & 0 \\
0 & 0 & 0
\end{array}\right), \Gamma=\left(\begin{array}{ccc}
1 & 0 & -(\rho \gamma+\kappa \theta) \\
0 & 1 & -\gamma \\
0 & 0 & 0
\end{array}\right) .
$$

The following properties hold for general values of the parameters. The characteristic polynomial associated with (2.1), $\left|I(1-z)^{2}-\Pi z+\Gamma z(1-z)\right|$, has three unit roots and no further roots. The levels coefficient matrix $\Pi$ has reduced rank $r=1$. It can be decomposed as $\Pi=\alpha \beta^{\prime}$ with $\alpha=(-1,0,0)^{\prime}$ and $\beta=(1,-\rho, 0)^{\prime}$. The orthogonal complements can be chosen as

$$
\alpha_{\perp}=\left(\begin{array}{cc}
0 & 0 \\
\frac{1}{1+\rho^{2}} & 0 \\
0 & 1
\end{array}\right), \beta_{\perp}=\left(\begin{array}{cc}
\rho & \rho \gamma \\
1 & \gamma \\
-\gamma\left(1+\rho^{2}\right) & 1
\end{array}\right)
$$

The second matrix in (2.2),

$$
\alpha_{\perp}^{\prime} \Gamma \beta_{\perp}=\left(\begin{array}{cc}
\frac{\theta}{1+\rho^{2}} & 0 \\
0 & 0
\end{array}\right)
$$


has reduced rank $s=1$. It may be decomposed as $\alpha_{\perp}^{\prime} \Gamma \beta_{\perp}=\xi \eta^{\prime}$ with $\xi=$ $\left(\frac{1}{\left(1+\rho^{2}\right)^{2}}, 0\right)^{\prime}, \eta=\left(\theta\left(1+\rho^{2}\right), 0\right)^{\prime}$. The orthogonal complements can be chosen as $\xi_{\perp}=(0,1)^{\prime}$ and $\eta_{\perp}=(0,1)^{\prime}$. It follows that $\alpha_{1}=\bar{\alpha}_{\perp} \xi=\left(0, \frac{1}{1+\rho^{2}}, 0\right)^{\prime}$, $\alpha_{2}=\alpha_{\perp} \xi_{\perp}=(0,0,1)^{\prime}$,

$$
\beta_{1}=\bar{\beta}_{\perp} \eta=\left(\begin{array}{c}
\rho \\
1 \\
-\gamma\left(1+\rho^{2}\right)
\end{array}\right) \text {, and } \beta_{2}=\beta_{\perp} \eta_{\perp}=\left(\begin{array}{c}
\rho \gamma \\
\gamma \\
1
\end{array}\right) \text {. }
$$

The standard representation (2.4) of the polynomially cointegrating parameter is

$$
\delta=\bar{\alpha}^{\prime} \Gamma \bar{\beta}_{2}=\kappa .
$$

Assumption 1 is satisfied since the roots of the characteristic polynomial remain outside the unit circle or at one, $\operatorname{rank}(\Pi)=r<p, \operatorname{rank}\left(\alpha_{\perp}^{\prime} \Gamma \beta_{\perp}\right)=$ $s<p-r$, and

$$
\left|\alpha_{2}^{\prime}\left(\Gamma \bar{\beta} \bar{\alpha}^{\prime} \Gamma+I-\Gamma\right) \beta_{2}\right|=1 \neq 0 .
$$

Note that the rank conditions do not depend on the parameters for this particular DGP.

\section{References}

[1] Baba, Y., Hendry, D. F., and Starr, R.M. (1992), The Demand for M1 in the U.S.A., 1960-1988, Review of Economic Studies, 59(1), 25-61.

[2] Banerjee, A., Cockerell, L., and Russell, B. (2001), An I(2) analysis of inflation and the markup, Journal of Applied Econometrics, 16, 221240 .

[3] Banerjee, A. and Russell, B. (2001), The Relationship between the Markup and Inflation in the G7 Economies and Australia, Review of Economics and Statistics, 83 (2), 377-384.

[4] Coenen, G., and Vega, J.-L., (2001), The Demand for M3 in the Euro Area, Journal of Applied Econometrics, 16, 727-748.

[5] Doornik, J., Hendry, D. and Nielsen, B. (1998), Inference in Cointegrating Models: UK M1 Revisited, Journal of Economic Surveys, 12, 533-572.

[6] Ericsson, N. (1998), Empirical Modelling of Money Demand, Empirical Economics 23(3), 295-315. 
[7] Ericsson, N., Hendry, D. F., and Prestwich, K. M., (1998), The Demand for Broad Money in the United Kingdom, 1878-1993, Scandinavian Journal of Economics, 100 (1), 289-324.

[8] Friedman, B. M., and Kuttner, K. N. (1992), Money, Income, Prices, and Interest Rates, American Economic Review 82(3), 472-92.

[9] Goldfeld, S. M. (1973), The Demand for Money Revisited, Brookings Papers on Economic Activity, 3, 577-638.

[10] Goldfeld, S. M. (1976), The Case of the Missing Money, Brookings Papers on Economic Activity, 3(76), 683-730.

[11] Granger, C. (1986), Developments in the Study of Cointegrated Economic Variables, Oxford Bulletin of Economics and Statistics, 48(3), 213-28.

[12] Haldrup, N. (1998), An Econometric Analysis of I(2) Variables, Journal of Economic Surveys, 12, 595-650.

[13] Hansen, P.R. and Johansen, S. (1998), Workbook on Cointegration, Oxford University Press, Oxford.

[14] Johansen, S. (1988), Statistical Analysis of Cointegration Vectors, Journal of Economic Dynamics and Control, 12, 231-54.

[15] Johansen, S. (1992a), A Representation of Vector Autoregressive Processes Integrated of Order 2, Econometric Theory, 8, 188-202.

[16] Johansen, S. (1992b), Determination of cointegration rank in the presence of a linear trend, Oxford Bulletin of Economics and Statistics, 54, 383-97.

[17] Johansen, S. (1995), A Statistical Analysis of Cointegration for I(2) Variables, Econometric Theory, 11, 25-59.

[18] Johansen, S. (1996), Likelihood Based Inference in Cointegrated Vector Autoregressive Models, 2nd edition, Oxford University Press, Oxford.

[19] Johansen, S. (1997), A Likelihood analysis of the I(2) Model, Scandinavian Journal of Statistics, 24, 433-462.

[20] Juselius, K. (1999), Price convergence in the medium and long run: An $\mathrm{I}(2)$ analysis of six price indices, in Engle, R.F. and White, H. (eds.): 
Cointegration, Causality, and Forecasting: A Festschrift in Honour of Clive Granger, Oxford University Press, Oxford.

[21] Juselius, K. (2001), European Integration and Monetary Transmission Mechanisms: The Case of Italy, Journal of Applied Econometrics, 16(3), 341-58.

[22] Juselius, K., and Toro, J. (1999), The Effect of Joining the EMS: Monetary Transmission Mechanisms in Spain, University of Copenhagen, Institute of Economics Discussion Paper 99/22, October 1999.

[23] Kongsted, H. C. (1998), An I(2) Cointegration Analysis of SmallCountry Import Price Determination, Discussion paper 98-22, December 1998, Institute of Economics, University of Copenhagen.

[24] Kongsted, H. C., and Nielsen, H. B. (2002), Analyzing I(2) Systems by Transformed Vector Autoregressions, working paper, Institute of Economics, University of Copenhagen.

[25] MacKinnon, J. G., Haug, A. A., and Michelis, L. (1999), Numerical Distribution Functions of Likelihood Ratio Tests for Cointegration, Journal of Applied Econometrics, 14(5), 563-77.

[26] Muscatelli, V. A., and Spinelli, F. (2000), The Long-Run Stability of the Demand for Money: Italy 1861-1996, Journal of Monetary Economics 45(3), 717-39.

[27] Nielsen, B. and Rahbek, A. (1998), Similarity Issues in Cointegration Analysis, Oxford Bulletin of Economics and Statistics, 62(1), 5-22.

[28] Paruolo, P. (1996), On the determination of integration indices in I(2) Systems, Journal of Econometrics, 72, 313-356.

[29] Paruolo, P. and Rahbek., A. (1999), Weak Exogeneity in I(2) VAR Systems, Journal of Econometrics, 93(2), 281-308.

[30] Rahbek, A., Kongsted, H. C., and Jørgensen, C. (1999), Trend Stationarity in the I(2) Cointegration Model, Journal of Econometrics, 90, 265-289.

[31] Stock, J. H., and Watson, M. W., A Simple Estimator of Cointegrating Vectors in Higher Order Integrated Systems, Econometrica, 61(4), 783820 . 
Table 1: Three special cases of the simulation model.

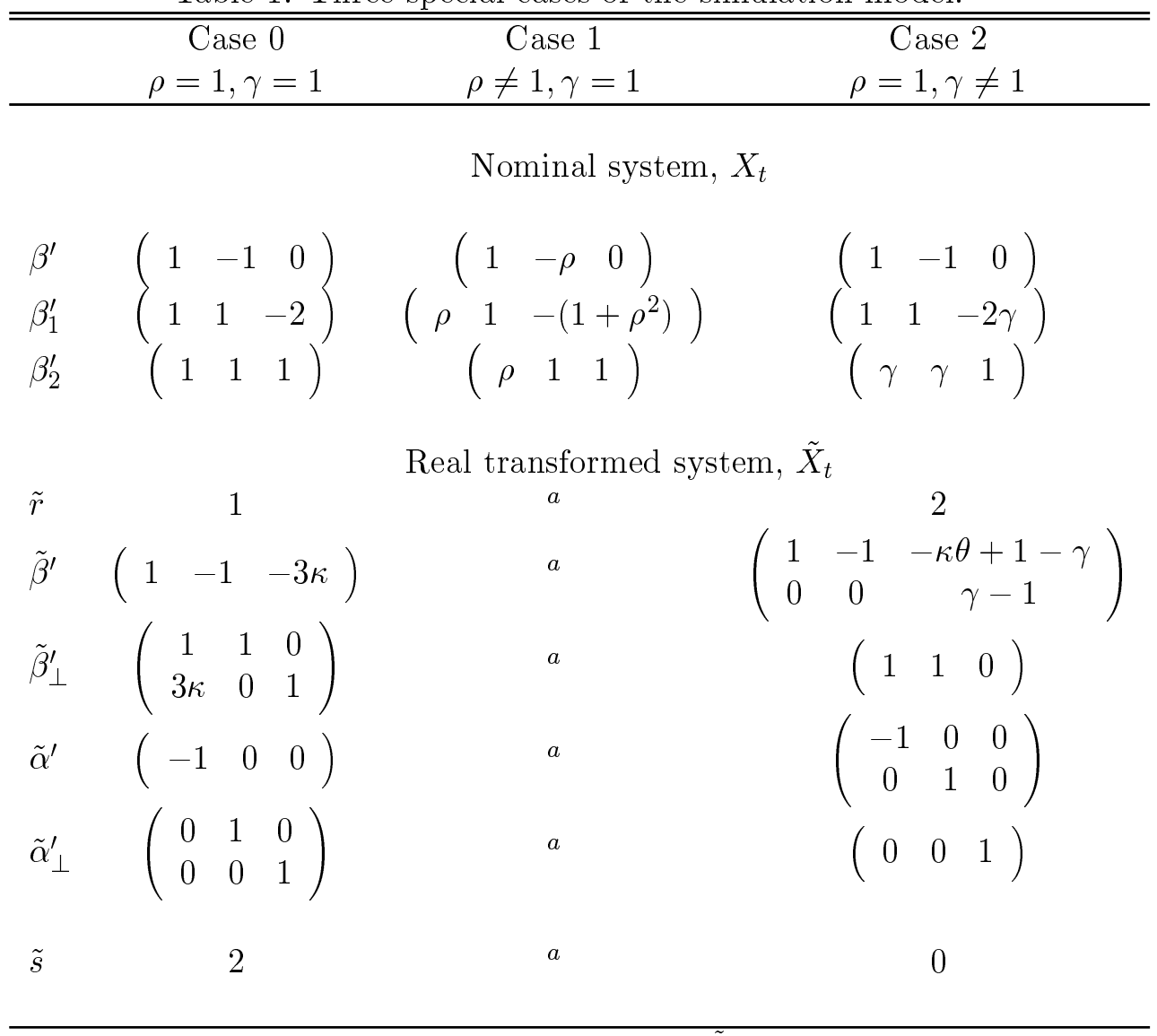

${ }^{a}$ No VEC representation in terms of $\tilde{X}_{t}$ for this case. 
Table 2: Simulation results. $\nu=.05 .10 .000$ replications.

\begin{tabular}{|c|c|c|c|c|c|c|c|c|}
\hline & \multirow[b]{2}{*}{$\rho$} & \multirow[b]{2}{*}{$\gamma$} & \multirow[b]{2}{*}{$T$} & \multicolumn{2}{|c|}{ Rejection Frequency } & \multicolumn{3}{|c|}{ Rank Determination } \\
\hline & & & & $Q_{b 1}$ & Seq. Test & $\tilde{r}=1$ & $\tilde{r}=2$ & $\tilde{r}=3$ \\
\hline \multirow[t]{3}{*}{ Case 0} & 1 & 1 & 50 & 0.080 & 0.088 & 0.920 & 0.070 & 0.010 \\
\hline & & & 150 & 0.054 & 0.059 & 0.941 & 0.053 & 0.005 \\
\hline & & & 500 & 0.054 & 0.050 & 0.948 & 0.047 & 0.005 \\
\hline \multirow[t]{11}{*}{ Case 1} & 0.999 & 1 & 50 & 0.140 & 0.134 & $a$ & $a$ & $a$ \\
\hline & & & 150 & 0.688 & 0.646 & $a$ & $a$ & $a$ \\
\hline & & & 500 & 1.000 & 0.999 & $a$ & $a$ & $a$ \\
\hline & 0.998 & 1 & 50 & 0.282 & 0.255 & $a$ & $a$ & $a$ \\
\hline & & & 150 & 0.901 & 0.888 & $a$ & $a$ & $a$ \\
\hline & & & 500 & 1.000 & 1.000 & $a$ & $a$ & $a$ \\
\hline & 0.995 & 1 & 50 & 0.633 & 0.599 & $a$ & $a$ & $a$ \\
\hline & & & 150 & 0.994 & 0.992 & $a$ & $a$ & $a$ \\
\hline & 0.990 & 1 & 50 & 0.867 & 0.847 & $a$ & $a$ & $a$ \\
\hline & & & 150 & 1.000 & 1.000 & $a$ & $a$ & $a$ \\
\hline & 0.980 & 1 & 50 & 0.967 & 0.961 & $a$ & $a$ & $a$ \\
\hline \multirow[t]{21}{*}{ Case 2} & 1 & 0.999 & 50 & 0.081 & 0.088 & 0.922 & 0.070 & 0.009 \\
\hline & & & 150 & 0.055 & 0.061 & 0.940 & 0.053 & 0.006 \\
\hline & & & 500 & 0.051 & 0.059 & 0.943 & 0.052 & 0.005 \\
\hline & 1 & 0.998 & 50 & 0.086 & 0.093 & 0.923 & 0.068 & 0.009 \\
\hline & & & 150 & 0.061 & 0.069 & 0.941 & 0.053 & 0.006 \\
\hline & & & 500 & 0.053 & 0.100 & 0.927 & 0.064 & 0.009 \\
\hline & 1 & 0.995 & 50 & 0.077 & 0.094 & 0.918 & 0.072 & 0.009 \\
\hline & & & 150 & 0.062 & 0.098 & 0.929 & 0.063 & 0.008 \\
\hline & & & 500 & 0.053 & 0.335 & 0.788 & 0.183 & 0.028 \\
\hline & 1 & 0.990 & 50 & 0.077 & 0.113 & 0.913 & 0.074 & 0.012 \\
\hline & & & 150 & 0.055 & 0.212 & 0.869 & 0.111 & 0.019 \\
\hline & & & 500 & 0.052 & 0.675 & 0.465 & 0.479 & 0.055 \\
\hline & 1 & 0.980 & 50 & 0.080 & 0.203 & 0.878 & 0.104 & 0.018 \\
\hline & & & 150 & 0.057 & 0.489 & 0.664 & 0.294 & 0.042 \\
\hline & & & 500 & 0.053 & 0.939 & 0.096 & 0.827 & 0.077 \\
\hline & 1 & 0.950 & 50 & 0.084 & 0.531 & 0.655 & 0.289 & 0.056 \\
\hline & & & 150 & 0.059 & 0.887 & 0.198 & 0.721 & 0.081 \\
\hline & & & 500 & 0.060 & 1.000 & 0.000 & 0.918 & 0.082 \\
\hline & 1 & 0.900 & 50 & 0.086 & 0.803 & 0.384 & 0.520 & 0.096 \\
\hline & & & 150 & 0.061 & 0.991 & 0.017 & 0.880 & 0.095 \\
\hline & & & 500 & 0.053 & 1.000 & 0.000 & 0.923 & 0.077 \\
\hline
\end{tabular}

\footnotetext{
Note: $Q_{b 1}$ is the Johansen (1995) likelihood ratio test of $b^{\prime} \beta=0$. Seq. Test is the sequential test of $b^{\prime}\left(\beta, \beta_{1}\right)=0$, see Kongsted (1998). Rank Determination uses the procedure described by Johansen (1992b) based on the trace test of Johansen (1988).

${ }^{a}$ No VEC representation in terms of $\tilde{X}_{t}$ for this case.
} 
Table 3: Main characteristics of the data.

\begin{tabular}{|c|c|c|c|c|c|c|}
\hline \multirow[b]{2}{*}{ Country } & \multirow[b]{2}{*}{ Sample } & \multicolumn{4}{|c|}{ Variable definitions } & \multirow[b]{2}{*}{ Source } \\
\hline & & $m_{t}$ & $p_{t}$ & $y_{t}$ & $R_{t}$ & \\
\hline U.S. & $\begin{array}{c}1900 \\
-1989\end{array}$ & M1 & $\begin{array}{l}\text { Deflator of net } \\
\text { national product }\end{array}$ & $\begin{array}{l}\text { Net national } \\
\text { product }\end{array}$ & $\begin{array}{l}\text { Commercial } \\
\text { paper rate }\end{array}$ & $\begin{array}{l}\text { Stock and } \\
\text { Watson (1993) }\end{array}$ \\
\hline U.K. & $\begin{array}{c}1871 \\
-1993\end{array}$ & $\begin{array}{l}\text { Broad } \\
\text { money }\end{array}$ & $\begin{array}{l}\text { Deflator of net } \\
\text { national income }\end{array}$ & $\begin{array}{l}\text { Net national } \\
\text { income }\end{array}$ & $\begin{array}{l}\text { Short-term } \\
\text { interest rate }\end{array}$ & $\begin{array}{l}\text { Ericsson } \\
\text { et al. (1998) }\end{array}$ \\
\hline Italy & $\begin{array}{c}1861 \\
-1996\end{array}$ & M2 & $\begin{array}{l}\text { Cost-of-living } \\
\text { index }\end{array}$ & Real GDP & $\begin{array}{l}\text { Long-term } \\
\text { government } \\
\text { bond yield }\end{array}$ & $\begin{array}{l}\text { Muscatelli and } \\
\text { Spinelli (2000) }\end{array}$ \\
\hline & & & & & Deposit rate & \\
\hline
\end{tabular}

Note: The Stock and Watson (1993) data set was obtained from Mark Watsons homepage. David Hendry kindly supplied the data used in Ericsson et al. (1998). The appendix to Muscatelli and Spinelli (2000) lists their data.

Table 4: Tests of the nominal-to-real transformation.

\begin{tabular}{|c|c|c|c|c|c|}
\hline \multirow[b]{2}{*}{ Country } & \multirow[b]{2}{*}{$v_{1}, v_{2}$} & \multicolumn{2}{|c|}{ Constant and trend } & \multicolumn{2}{|c|}{ Constant } \\
\hline & & $Q_{b 1}\left(v_{1}\right)$ & $Q_{b 2}\left(v_{2}\right)$ & $Q_{b 1}\left(v_{1}\right)$ & $Q_{b 2}\left(v_{2}\right)$ \\
\hline U.S. & 1,2 & $1.68[.20]$ & $2.93[.23]$ & $1.67[.20]$ & $1.34[.51]$ \\
\hline U.K. & 1,2 & $.12[.73]$ & $2.80[.25]$ & $3.10[.08]$ & $1.61[.45]$ \\
\hline Italy & 1,3 & $.14[.71]$ & $36.12[.00]$ & $3.52[.06]$ & $34.55[.00]$ \\
\hline
\end{tabular}

Note: Values in brackets are $p$-values. 